\title{
Long-term spatial-temporal trends and variability of rainfall over Eastern and Southern Africa
}

\author{
Francis Kamau Muthoni ${ }^{1}$ (D) Vincent Omondi Odongo $0^{2,3} \cdot$ Justus Ochieng $^{4} \cdot$ Edward M. Mugalavai $^{5}$. \\ Sixbert Kajumula Mourice ${ }^{6} \cdot$ Irmgard Hoesche-Zeledon $^{7} \cdot$ Mulundu Mwila $^{8} \cdot$ Mateete Bekunda $^{1}$
}

Received: 4 June 2018 / Accepted: 7 November 2018 / Published online: 20 November 2018

(C) The Author(s) 2018

\begin{abstract}
This study investigates the spatial-temporal trends and variability of rainfall within East and South Africa (ESA) region. The newly available Climate Hazards group Infrared Precipitation with Stations (CHIRPS-v2) gridded data spanning 37 years (1981 to 2017) was validated against gauge observations $(N=4243)$ and utilised to map zones experiencing significant monotonic rainfall trends. Standardised annual rainfall anomalies revealed the spatial-temporal distribution of below and above normal rains that are associated with droughts and floods respectively. Results showed that CHIRPS-v2 data had a satisfactory skill to estimate monthly rainfall with Kling-Gupta efficiency (KGE $=0.68$ and a high temporal agreement $(r=0.73)$ while also preserving total amount $(\beta=0.99)$ and variability $(\gamma=0.8)$. Two contiguous zones with significant increase in annual rainfall $\left(3-15 \mathrm{~mm} \mathrm{year}^{-1}\right)$ occurred in Southwest Zambia and in Northern Lake Victoria Basin between Kenya and Uganda. The most significant decrease in annual rainfall ($20 \mathrm{~mm}$ year $^{-1}$ ) was recorded at Mount Kilimanjaro in Tanzania. Other significant decreases in annual rainfall ranging between -4 and $-10 \mathrm{~mm}$ year $^{-1}$ were observed in Southwest Tanzania, Central-South Kenya, Central Uganda and Western Rwanda. CHIRPS-v2 rainfall product provides reliable high spatial resolution information on amount of rainfall that can complement sparse rain gauge network in rain-fed agricultural systems in ESA region. The observed spatial-temporal trends and variability in rainfall are important basis for guiding targeting of appropriate adaptive measures across multiple sectors.
\end{abstract}

Electronic supplementary material The online version of this article (https://doi.org/10.1007/s00704-018-2712-1) contains supplementary material, which is available to authorized users.

Francis Kamau Muthoni

fkmuthoni@gmail.com; f.muthoni@cgiar.org

Vincent Omondi Odongo

vincent.odongo@wur.nl

Justus Ochieng

justus.ochieng@worldveg.org

Edward M. Mugalavai

emugalavai@mmust.ac.ke

Sixbert Kajumula Mourice

sixbert.mourice@suanet.ac.tz

Irmgard Hoesche-Zeledon

I.Hoeschle-Zeledon@cgiar.org

Mulundu Mwila

mwilamulundu@gmail.com
1 International Institute of Tropical Agriculture (IITA), P.O. Box 10, Duluti, Arusha, Tanzania

2 Water Resources Management Group, Wageningen University, P. O. Box 47, 6700 AA Wageningen, The Netherlands

3 Department of Agricultural Engineering, Egerton University, P.O Box 536, Njoro, Kenya

4 World Vegetable Center, P.O. Box 10, Duluti, Arusha, Tanzania

5 Masinde Muliro University of Science and Technology, P.O Box 190 - 50100, Kakamega, Kenya

6 Department of Crop Science and Production, Sokoine University of Agriculture, P. O. Box 3005, Morogoro, Tanzania

7 International Institute of Tropical Agriculture (IITA), PMB 5320, Oyo Road, Ibadan, Oyo State 200001, Nigeria

8 Msekera Research Station, Zambia Agriculture Research Institute, P.O Box 510089, Chipata, Zambia 


\section{Introduction}

There is an increasing body of evidence supporting that climate change and variability have significant impact on ecosystem health (Bartzke et al. 2018) and agricultural production (Craparo et al. 2015; Niles et al. 2015; Lobell et al. 2011). Future projections in the East and Southern Africa (ESA) region points to wetter climate (Otte et al. 2017; IPCC 2014) although erratic rainfall patterns and frequent extreme events such as droughts and floods are common (Nicholson 2016; Guan et al. 2014). Over 70\% of livelihoods in ESA region depends on rain-fed agriculture, therefore highly vulnerable to climate change and variability (Ochieng et al. 2017). Therefore, understanding the spatial and temporal patterns of climate change and variability is a key step towards designing and targeting appropriate adaptation strategies.

Climatic extremes with adverse effects on crops and ecosystems include droughts, flooding, hail storms, heat waves and frost or their combinations. Increased frequency of climatic extremes has significant effect on structure, functions, land use patterns and livelihoods in agroecosystems (Adhikari et al. 2015). Rainfall is the most important limiting factor in rain-fed farming systems in Africa (Niles et al. 2015) since it determines availability of soil moisture required for potential productivity. The amount and distribution of rainfall determines suitability of crop varieties and related agronomic management at different locations (Muthoni et al. 2017). Low or sub-optimal rainfall cause agricultural drought that retard plant growth and reduced yields (Zampieri et al. 2017; Zipper et al. 2016) while extremely high rainfall events cause floods that destroy crops. However, impacts of climatic extremes vary in importance over space and time depending on different farming systems, agro-ecologies and ability of farmers to adapt (Niles et al. 2015). Climate change is projected to reduce as much as $40 \%$ of maize yields in East Africa by the end of twenty-first Century (Adhikari et al. 2015). Moreover, changes in rainfall regime accentuate proliferation of new crop pests and diseases (Kumar et al. 2014).

Previous studies on rainfall trends in ESA region largely used gauge station data, e.g. in Kenya (Odongo et al. 2015), in Tanzania (Otte et al. 2017), in Zambia (Goenster et al. 2015; Kampata et al. 2008) and Uganda (Onyutha 2016a; Kizza et al. 2009). The above studies aimed at understanding rainfall trends at catchments or basin scale although agricultural policies are increasingly focusing on mega-environments that cuts across several countries. Moreover, gauge stations are sparsely distributed in rural Africa, despite the high variability in topography and other biophysical environments (Toté et al. 2015). The sparse distribution is confounded with temporally incomplete records that introduce uncertainties when gauged data is used for designing early warning and decision support tools. Recent progress has demonstrated that synergistic blending of data from gauge stations and remote sensing satellites can reliably present the spatial-temporal distribution of rainfall over extensive areas (Maidment et al. 2017; Dembélé and Zwart 2016; Trejo et al. 2016; Funk et al. 2015; Toté et al. 2015; Asadullah et al. 2008; Dinku et al. 2007). The repetitive and near global coverage of remote sensing platform compliments the gauge data by providing more intuitive spatial-temporal patterns of rainfall to improve decision support applications such as drought monitoring and early warning systems (Funk et al. 2015; Toté et al. 2015).

This study utilises Climate Hazards group Infrared Precipitation with Stations version two (CHIRPS-v2) data to analyse long-term trends and variability of rainfall (19812017) in ESA region. The trend analyses identify zones experiencing significant increasing or decreasing rainfall trends. This information is helpful in quantifying the magnitude of risks posed by climate change and variability to guide prioritisation of scarce resources by directing appropriate measures to most vulnerable zones. The study hypothesise that understanding past trends in climate can inform future trajectories to support decisions on spatial targeting of appropriate adaptive measures. We posit that CHIRPS-v2 rainfall estimates offer a reliable dataset for monitoring spatial-temporal trends and variability of rainfall over regions with low density of ground observation stations in Africa.

\section{Material and methods}

\subsection{Study area}

The study area is approximately 2.73 million $\mathrm{km}^{2}$ occurring in seven countries within ESA region (Fig. 1). Rainfall in Northern Tanzania, Burundi, Rwanda, Kenya and Uganda shows a bimodal rainfall pattern. The long rainy season occurs in March, April and May (MAM) and the short rainy season in October, November and December (OND). Rains in Malawi, Zambia and Central-Southern Tanzania, are largely unimodal starting in October and ending in April but exhibit high spatial-temporal variability. Variability in rainfall is mainly determined by northsouth movement of the Intertropical Convergence Zone (ITCZ) (Diem et al. 2014) and changes in sea surface temperatures, especially in the tropical pacific (Maidment et al. 2015), El-Niño Southern Oscillation (ENSO); though relief features like Mount Kilimanjaro and inland large water bodies play a role in small-scale variations in rainfall. Droughts are frequent with occurrence of at least once in a 5-year cycle (Nicholson 2016).

\subsection{Gauge and satellite rainfall data}

The last few decades has witnessed considerable increase of satellite-derived rainfall products with reasonable high spatial 


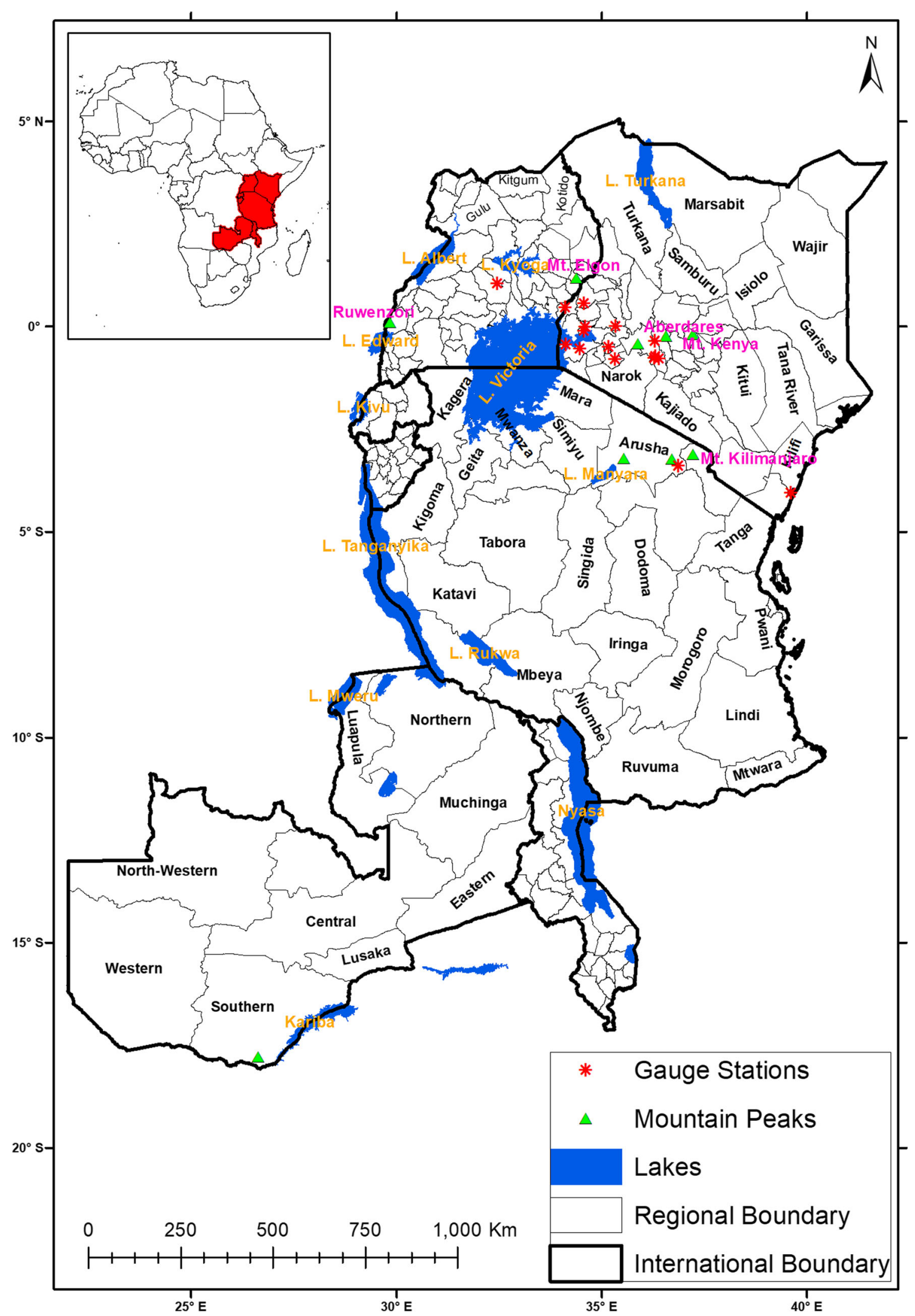

Fig. 1 The study area covering 7 countries in Eastern and Southern Africa (ESA) region and location of available rain gauge data used for evaluating CHIRPS-v2 data 
and temporal resolution. Characteristics of some of freely available hybrid gridded rainfall products are summarised in Table 1. The input data for algorithms that estimate hybrid satellite rainfall products is obtained from (1) thermal infrared (TIR) sensors only (e.g. Arkin and Meisner 1987); (2) passive microwave (PMW) sensors only (e.g. Kummerow et al. 2001) and (3) TIR and/or PMW sensors and/or gauge stations observations and/or model-based climatologies (e.g. Funk et al. 2015; Huffman et al. 2007; Xie and Arkin 1997). Incorporating multiple sensors data in algorithms for estimating rainfall reduce the inherent sampling errors of satellite estimates (Toté et al. 2015). Rainfall products estimated using hybrid algorithms (e.g. CHIRPSv2) perform better especially on areas with complex meteorological patterns such as high elevations and coast lines (Kimani et al. 2017; Toté et al. 2015).

This study used gridded Climate Hazards group Infrared Precipitation with Stations version two (CHIRPS-v2) with $5.5 \mathrm{~km}$ spatial resolution (Funk et al. 2015). CHIRPS-v2 uses Tropical Rainfall Measuring Mission Multi-satellite Precipitation Analysis version 7 (TMPA-3B42-v7) to calibrate global Cold Cloud Duration (CCD) rainfall estimates. It uses interpolation of gauge station data and satellite-derived precipitation estimates to provide a global rainfall product with fairly low latency, high resolution, low bias and long period of record. We used monthly and annual time series data for the last 37 years (1981-2017). Lakes and large waterbodies were masked out from CHIRPS-v2 grids to analyse rainfall over land mass only.

\subsection{Statistical analysis}

\subsubsection{Validation of satellite and gauge data}

Rainfall records were obtained from 65 gauge stations for validating CHIRPS-v2 rainfall estimates. Gauge records were obtained from different sources including Kenya meteorological department, individual farmers, agricultural research stations and the global historical climatology network (GHCN; Menne et al. 2012) database. The available gauge stations records were compared with the list of stations that were used in generating CHIRPS-v2 product per month from 1981 to 2016 (Funk et al. 2015). To ensure independent evaluation, only stations located more than ten kilometres radius from those initially used for generating CHIRPS-v2 were selected. Only 16 independent stations that had good quality data were utilised for evaluation (Online Resource 1(a)). Daily gauge records were aggregated to monthly totals resulting to $n=4243$ valid records after excluding data for months with any missing daily observation. Following (ZambranoBigiarini et al. 2017), the agreement between monthly CHIRPS-v2 and gauge station data was evaluated using modified Kling-Gupta efficiency (KGE) (Kling et al.
2012; Gupta et al. 2009) and decomposition of its three individual elements, i.e. Pearson product-moment correlation coefficient $(r)$, bias $(\beta)$, and variability $(\gamma)$. This goodness of fit statistics was derived using "HydroGOF" R package (Zambrano-Bigiarini 2018). KGE was selected based on general principle in hydrological applications that require rainfall estimates to be able to reproduce temporal dynamics (measured by $r$ ) while also preserving the volume (measured by $\beta$ ) and distribution of rainfall (measured by $\gamma$ ) (Zambrano-Bigiarini et al. 2017). The best value of $\mathrm{KGE}, r, \beta$ and $\gamma$ is 1.0. KGE varies from minus infinity to one with the values closer to 1 indicating that the estimated values more accurately mimic the observed values. The $r$ measures the linear correlation between time series of observed gauge data and satellite rainfall estimates. The $\beta$ measures the average tendency of the satellite values to be larger $(\beta>1$, overestimation) or smaller $(\beta<1$, underestimation) than gauge data. The $\gamma$ shows whether the dispersion of satellite estimates is higher or lower compared to observations. The $\gamma$ was derived using modified KGE that ensure bias and variability are not cross-correlated (Kling et al. 2012).

\subsubsection{Precipitation trend analysis}

The analysis was conducted in $\mathrm{R}$ for statistical computing $(\mathrm{R}$ Core Team 2018) mainly using the following packages: raster (Hijmans 2015), modifiedmk (Patakamuri 2018) and BiodiversityR (Kindt and Coe 2005). Long-term means (LTM) for annual and monthly CHIRPS-v2 rainfall were generated and plotted to visualise regional spatial-temporal patterns. The difference between total rainfall for each year and the LTM was divided by standard deviation to derive the annual rainfall anomalies. The anomalies indicate the departure from LTM with negative values representing periods of below normal rains (droughts) while positive values reveal above normal rains (flood risk). Spatial temporal variation was derived by calculating coefficient of variation (CV) for monthly and annual time series using raster package. This allowed detection of seasonality of monthly and annual rainfall time series.

Hydro-meteorological time series data are characterised by substantial departure from normality. For such data, the nonparametric methods are preferred for detecting monotonic trends because they have higher power than parametric methods (e.g. $t$ test). Non-parametric methods for detecting direction of monotonic trends in time series data include the Mann-Kendall (MK; Kendall 1975; Mann 1945), Spearman's Rho (SMR; Spearman 1904) and cumulative rank difference (CRD; Onyutha 2016b) tests. MK test considers ranks of the observations rather than their actual values and therefore it is less affected by the actual distribution of the data and is less sensitive to outliers (Yue et al. 2002a). CRD uses a concept 


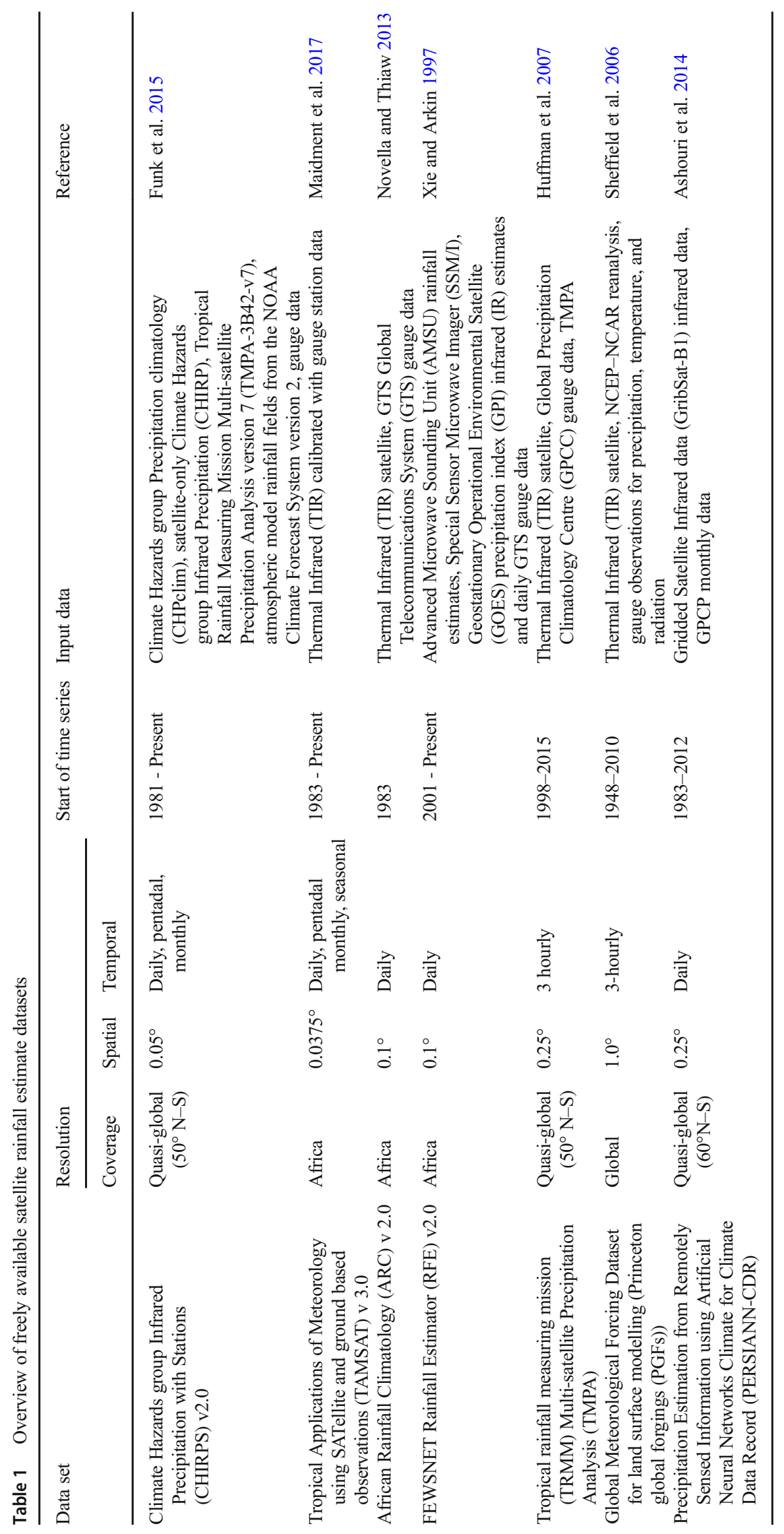


similar to Hurst rescaling (Hurst 1951) to analogously rescale the time series non-parametrically by calculating the difference between the exceedance and non-exceedance counts of data points (Onyutha 2016b). Cumulative sum of differences is used to separate sub-trends over unknown periods of increase or decrease in a time series. SMR is another nonparametric test that is used to detect whether correlation is present between two ranks in a time series data. A siginificant trend is detected if there is significant correlation between consequent time steps and the ranks of the observed time series data. The null hypothesis for the three tests statisticis is that there is no monotonic trend in a given time series data. In this study, MK was selected, although the three nonparametric tests are largely identical in their performance as demonstrated by Yue et al. (2002a) for MK and SMR, and Onyutha (2016b) for MK and CRD. MK was preferred because it is more frequently used for analysing trends in hydrometerological time series datasets compared to the other two methods (Yue et al. 2002a) and diverse forms of the algorithm are incorporated in many $\mathrm{R}$ packages.

MK tests assume that the time series data are independent and randomly ordered (Hamed and Rao 1998). Existence of serial autocorrelation and ties in time series data influence the magnitude of test statistic variance (Onyutha 2016c; Yue et al. 2002b). Positive autocorrelation inflates sampling variance of test statistic thus increasing probability of detecting trends when in reality none exists (type 1 error). Before conducting trend analysis, the significance of autocorrelation coefficients for monthly and annual time series data was tested at 5\% significant level. Data was considered auto-correlated if autocorrelation coefficient value exceeds the upper and lower bounds of the confidence interval. Diagnostic tests revealed marginal presence of serial dependence for annual and monthly time series (Online resource 1 b-c). In this study, the effect of serial dependence was taken into account by fitting a modified Mann-Kendall (MMK) procedure proposed by Hamed and Rao (1998). This procedure corrects the variance of test statistic if significant autocorrelation is detected in the first three lags. Variance correction was achieved using 'mmkh3lag' function in 'modifiedmk' R package (Patakamuri 2018). The magnitude or slope of the trend was quantified using the TheilSen method (Sen 1968; Theil 1950). The significant of trends and Theil-Sen slopes was evaluated at nominal significance level of $p<0.1$.

\section{Results}

\subsection{Validation of CHIRPS-v2 rainfall estimates}

CHIRPS-v2 rainfall showed high skill to estimate gauge observations in the ESA region $(\mathrm{KGE}=0.68)$. CHIRPS- v2 data also had high temporal agreement $(r=0.73)$ while also preserving total amount $(\beta=0.99)$ and variability $(\gamma=$ $0.8)$ compared to gauge observations. Scatterplot of two datasets revealed that CHIRPS-v2 rainfall over-estimated low-intensity rainfall below $100 \mathrm{~mm}$ and under-estimated high-intensity rainfall above $100 \mathrm{~mm}$ compared to gauge data (Fig. 2).

\subsection{Long-term spatial-temporal variability in rainfall}

LTM rainfall for 37 years in the ESA region ranged between 50 and $2400 \mathrm{~mm}$ (Fig. 3). The highest annual rainfall values were recorded around mountain peaks such as, Mt. Kilimanjaro, in Tanzania, Mt. Elgon in Uganda and Mt. Kenya, and Aberdare Ranges in Kenya that recorded values above $1700 \mathrm{~mm}$. The driest regions receiving less than $265 \mathrm{~mm}$ annual rainfall occurred in Northern Kenya.

The annual rainfall anomalies (Fig. 4) revealed that ESA region received above normal rainfall in 1982, 1989, 1997 and 2006, with the latter being the most severe. Significant large areas of ESA region experienced differing magnitude of drought during all the other years. Widespread droughts (below normal rainfall) was experienced in 1983, 1984, 1987, 1992, 1993, 1995, 1996, 1999, 2000, 2001, 2003 and 2005 across the ESA region. Long-term monthly rainfall series revealed that except in Uganda and western Kenya, June to September are dry seasons with rainfall less than $34 \mathrm{~mm}$ (Fig. 5).

Inter-annual variability was highest in North-Eastern Kenya ( $\mathrm{CV}=55 \%$; Fig. 6) coinciding with the lowest LTM

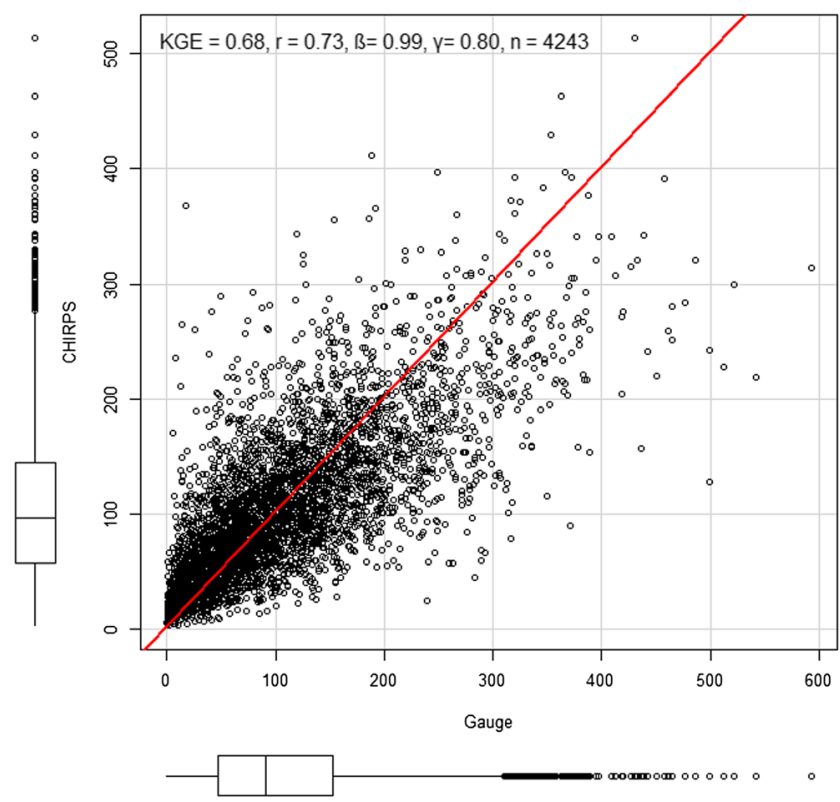

Fig. 2 Comparison of CHIRPS-v2 against observed gauge data. The solid line indicates 1:1 relationship 


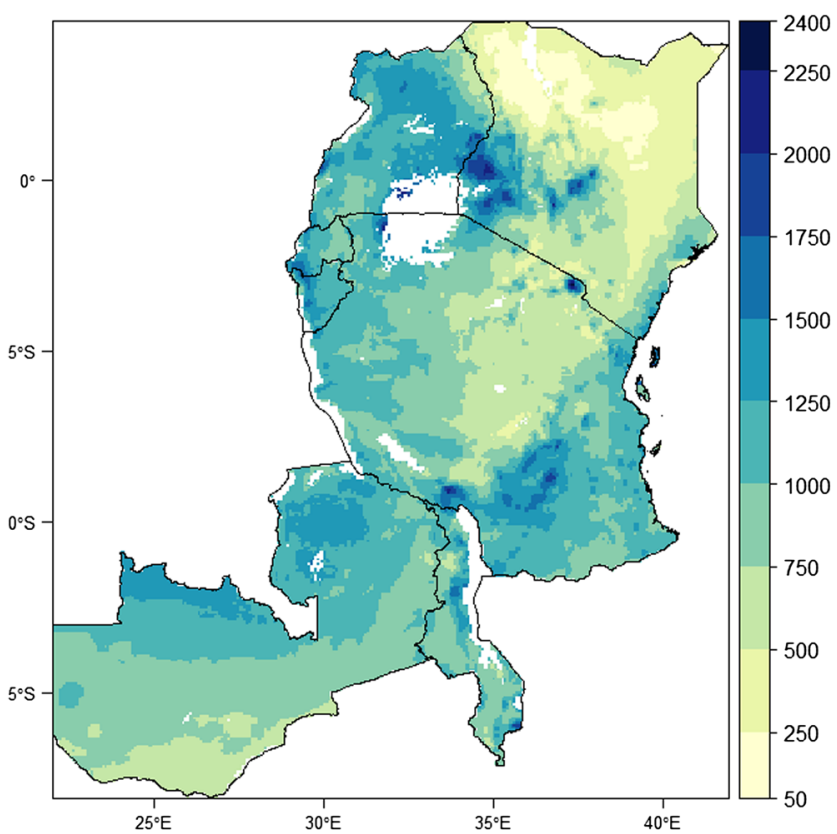

Fig. 3 Long-term mean annual (1981-2016) CHIRPS-v2 rainfall (mm) for 7 countries within Eastern and Southern Africa region

rainfall $(<265 \mathrm{~mm})$. A belt along Western Uganda, Rwanda, Burundi, Tanzania and Northwest Zambia had less than $10 \%$ $\mathrm{CV}$ in annual rainfall. In contrast, monthly rainfall was characterised by high inter-annual variability up-to $180 \%$ with January to March (JFM) rains in Kenya being the most variable $60-180 \%$ Fig. 7). Monthly rainfall in Rwanda and Burundi appeared relatively stable $(\mathrm{CV}<50 \%)$ compared to other countries, except for JJA ( $\mathrm{CV}>60 \%)$.

\subsection{Long-term monotonic trends for rainfall}

Results revealed variable spatial-temporal trends in annual and monthly rainfall with significant decrease or increase observed in different zones. Theil-Sen's slope for annual rainfall is presented in Fig. 8a, while Fig. 8 b shows locations where it was significant $(p<0.1)$. Generally, annual rainfall in Zambia revealed an increasing trajectory compared to a decreasing trajectory in the other 6 countries though in most instances the trend was not significant (Fig. 8). Annual rainfall in Zambia showed an increasing trend except for a small section in Northern Province that revealed low magnitude $(-0.1$ to $4 \mathrm{~mm}$ year $^{-1}$ ) significant decrease (Fig. 8b). The increasing annual rainfall in Zambia $\left(0-16 \mathrm{~mm}\right.$ year $\left.^{-1}\right)$ was significant in almost the entire Western, Southern, Central, Lusaka, and Copperbelt Provinces and extended to limited sections of all the other Provinces. The highest significant increase occurred in Western Province (8-16 mm year $\left.{ }^{-1}\right)$. The second largest contiguous zone with a trend of significantly increasing annual rainfall $\left(0-16 \mathrm{~mm}\right.$ year $\left.{ }^{-1}\right)$ occurred in Northern Lake Victoria Basin in a transboundary region between Western Kenya and Eastern Uganda (Fig. 8b). Moreover, an increase
Fig. 4 Standardised anomalies for annual rainfall in Eastern and Southern Africa region indicating the magnitude of departure from long-term mean rainfall (19812017). Negative values represent below normal while positive values represent above normal rainfall that are associated with droughts and floods respectively

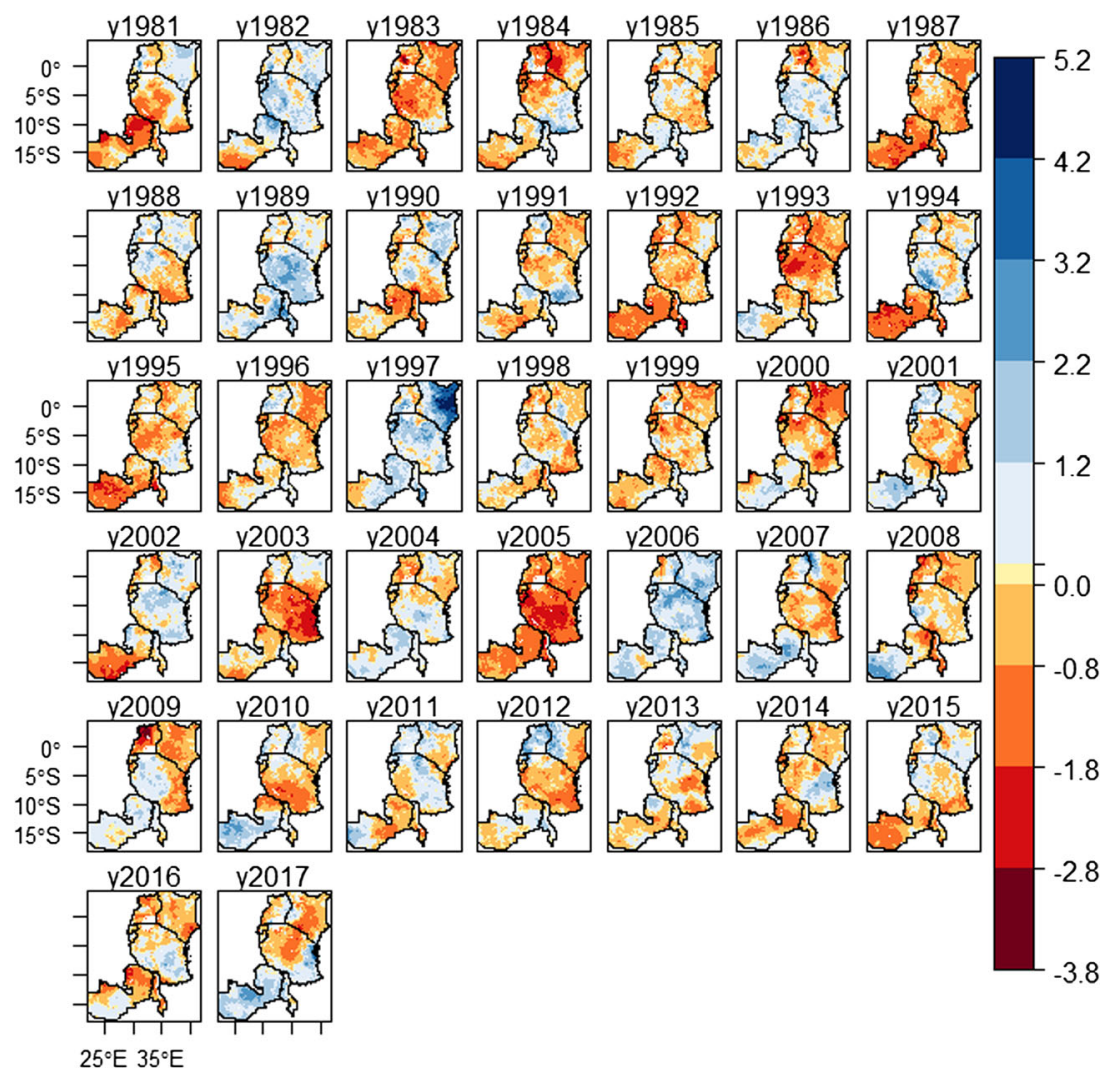


Fig. 5 Long-term mean (LTM) of total monthly rainfall $(\mathrm{mm})$ for 37 years (1981-2016) in 7 countries within Eastern and Southern Africa
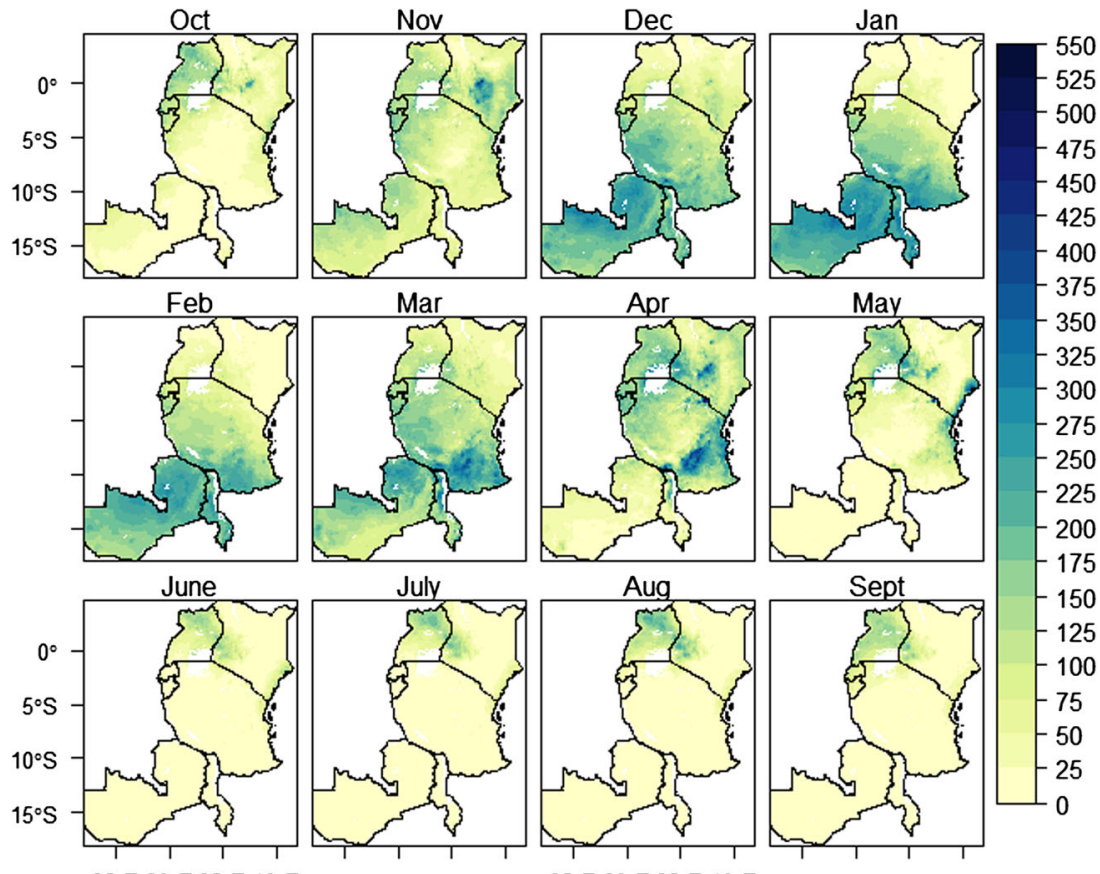

$25^{\circ} \mathrm{E} 30^{\circ} \mathrm{E} 35^{\circ} \mathrm{E} 40^{\circ} \mathrm{E}$ of less than $4 \mathrm{~mm} \mathrm{year}^{-1}$ was recorded around Lake Turkana in Kenya. In Tanzania, significant increase in annual rainfall (1-8 $\mathrm{mm} \mathrm{year}^{-1}$ ) was recorded in sections of Kagera,
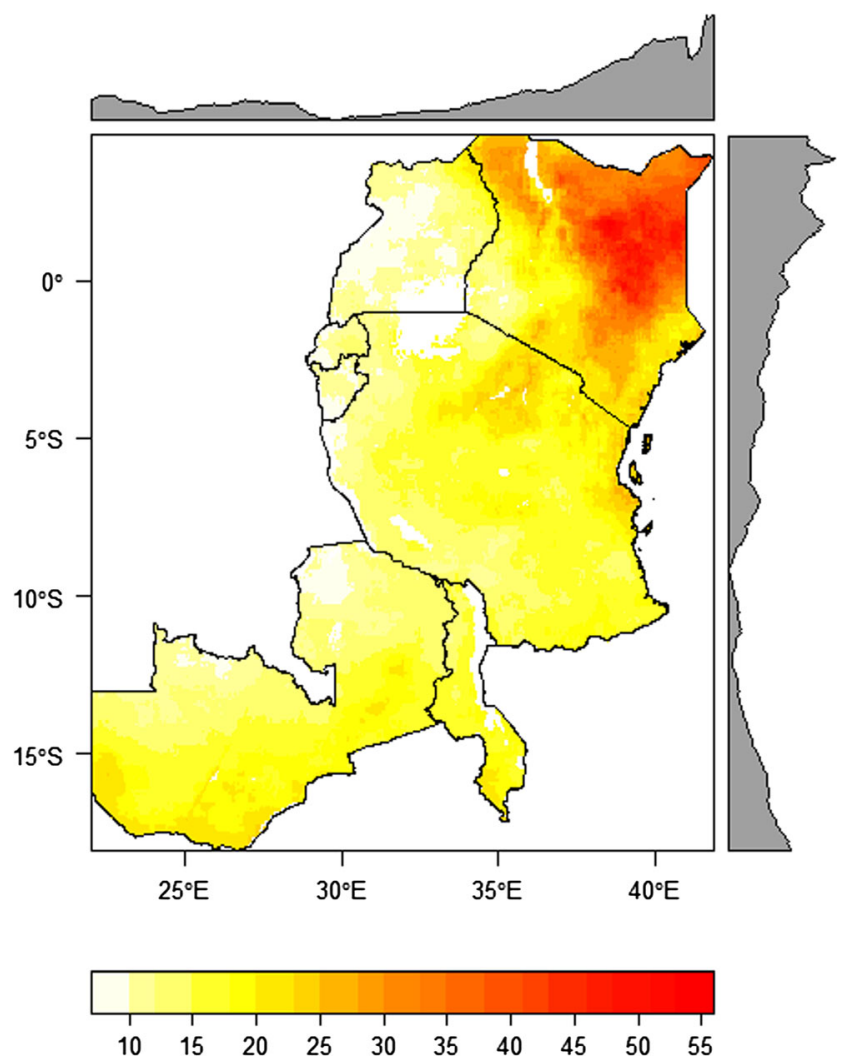

Fig. 6 Coefficient of variation (\%) of annual rainfall (1981-2016) in Eastern and Southern Africa region. The highest variability was recorded in the North-Eastern Kenya
Dodoma, Iringa and the area intersecting Simiyu, Mara and Arusha regions.

The highest significant decrease in annual rainfall was $19 \mathrm{~mm}$ year $^{-1}$ at Mount Kilimanjaro in Tanzania (Fig. 8b). The largest contiguous zone showing decreasing annual rainfall (0.1 to $-16 \mathrm{~mm}$ year $^{-1}$ ) was observed in North, central SouthEast Kenya covering Kitui, Makueni, Machakos, Kajiado, Taita Taveta, Tana River, Kwale, Kilifi, Garissa, Wajir, Isiolo, Embu, Tharaka-Nithi, Meru, Muranga and Kirinyaga counties. Moreover, in Tanzania significant decrease in annual rainfall ranging between -1 and $-12 \mathrm{~mm}$ year $^{-1}$ was observed in Ruvuma region and around Ngorongoro Crater in Arusha region. A decrease ranging between -1 and $-10 \mathrm{~mm}_{\text {year }}{ }^{-1}$ was observed in a contiguous zone South of Lake Kivu covering Southwest Rwanda and Northwest Burundi. Significant decrease in annual rainfall was observed in Central Uganda in a contiguous zone intersecting Southern Buganda, Western and Southern Provinces and around Gulu in Northern Province ( $<$ $-8 \mathrm{~mm}$ year $^{-1}$ ). Only a small area in Northern region of Malawi showed significant decline in annual rains $(<$ $8 \mathrm{~mm}$ year $^{-1}$ ).

Similarly, the monthly rainfall showed varied spatiotemporal trends. Figure 9 shows the monthly rainfall trends and Fig. 10 shows locations where the slopes were significant $(p<0.1)$. South-west Zambia experienced a significant increasing rainfall from November to January and March but was most pronounced in December (Fig. 10). Northern Lake Victoria Basin recorded increasing rainfall trends during the short rainy season that usually occurs between September and November with a more pronounced increase in October. November rainfall increased 
Fig. 7 Coefficient of variation (\%) of monthly rainfall (19812017) in Eastern and Southern Africa region
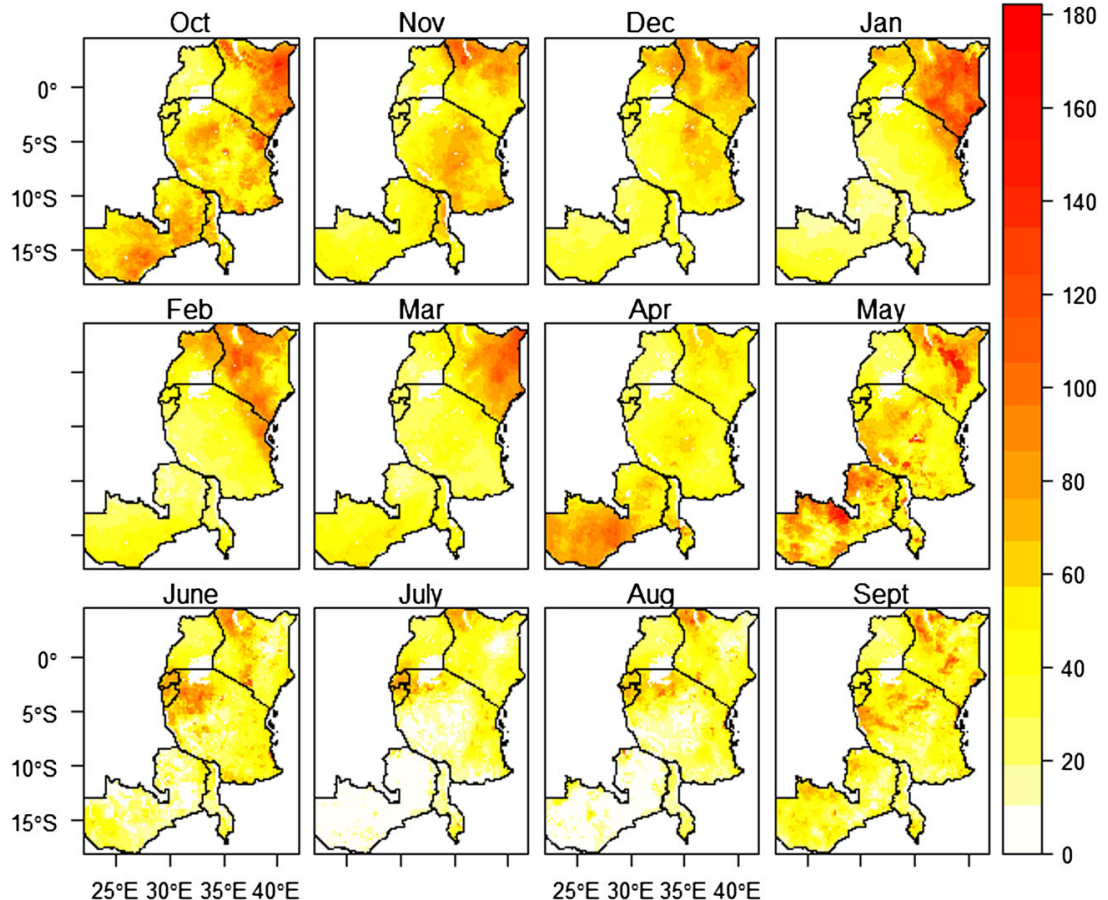

significantly in Central, North and East and along the coastal belt of Kenya.

The most pronounced decrease in monthly rainfall ( -0.9 to $3.6 \mathrm{~mm}$ year $^{-1}$ ) was observed on December rains in Central South-Eastern Kenya, South and South East Tanzania (Pwani, Lindi, Mtwara, Morogoro and Ruvuma regions; Fig. 10. A significant decline ( -0.1 to $3.6 \mathrm{~mm}$ year $^{-1}$ ) in April rains in Central, Southern and Northern Kenya occurred largely in the same counties where annual rainfall declined (Fig. 10). The decrease in annual rains in Central-west Uganda (Fig. 8) was majorly due to declines of rainfall experienced during the OND months (Fig. 10). There were also significant declines $\left(-1.8\right.$ to $\left.-2.7 \mathrm{~mm} \mathrm{year}^{-1}\right)$ in December rains observed in parts of Mzuzu in Northern region of Malawi.

\section{Discussions}

\subsection{Validation of CHIRPS-V2 with gauge rainfall}

Validation results revealed that CHIRPS-v2 data has high skill to estimate gauge observations in ESA region $(\mathrm{KGE}=0.68)$. It also showed high temporal agreement $(r=0.73)$ while also preserving total amount $(\beta=0.99)$ and variability $(\gamma=0.8)$ compared to gauge observations. Recent studies have reported similar high agreement in East Africa region (Dinku et al. 2018), in Ethiopia (Ayehu et al. 2017), in Chile (ZambranoBigiarini et al. 2017), in Venezuela (Trejo et al. 2016) and in Colombia (Funk et al. 2015). Dinku et al. (2018) reported high temporal correlation $(r>0.83)$ and low bias $(-4$ to $13 \%)$ after
Fig. 8 Monotonic trends for annual rainfall $\left(\mathrm{mm}_{\mathrm{ye}} \mathrm{r}^{-1}\right)$ in Eastern and Southern Africa (ESA) region for 1981-2017 period (a) and zones with significant $(p<0.1)$ increase or decrease in rainfall $(\mathbf{b})$
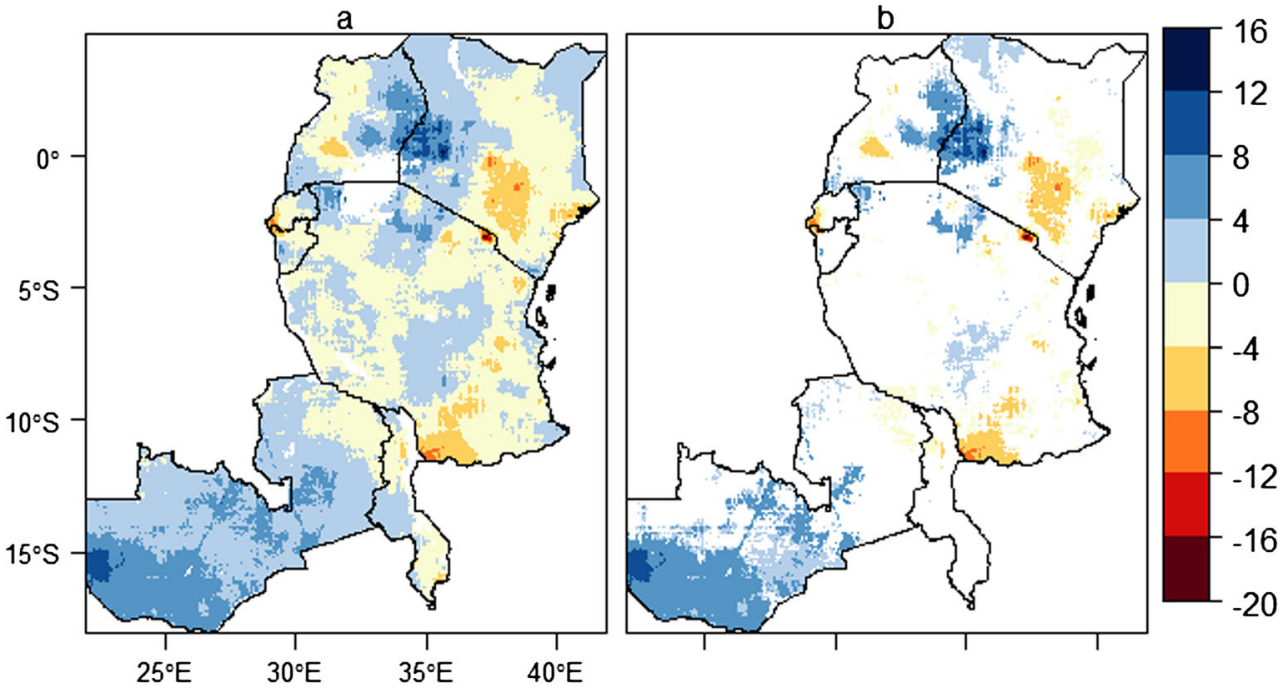
Fig. 9 Trends in monthly rainfall $\left(\mathrm{mm} \mathrm{year}^{-1}\right)$ for 1981-2017 in Eastern and Southern Africa (ESA) region

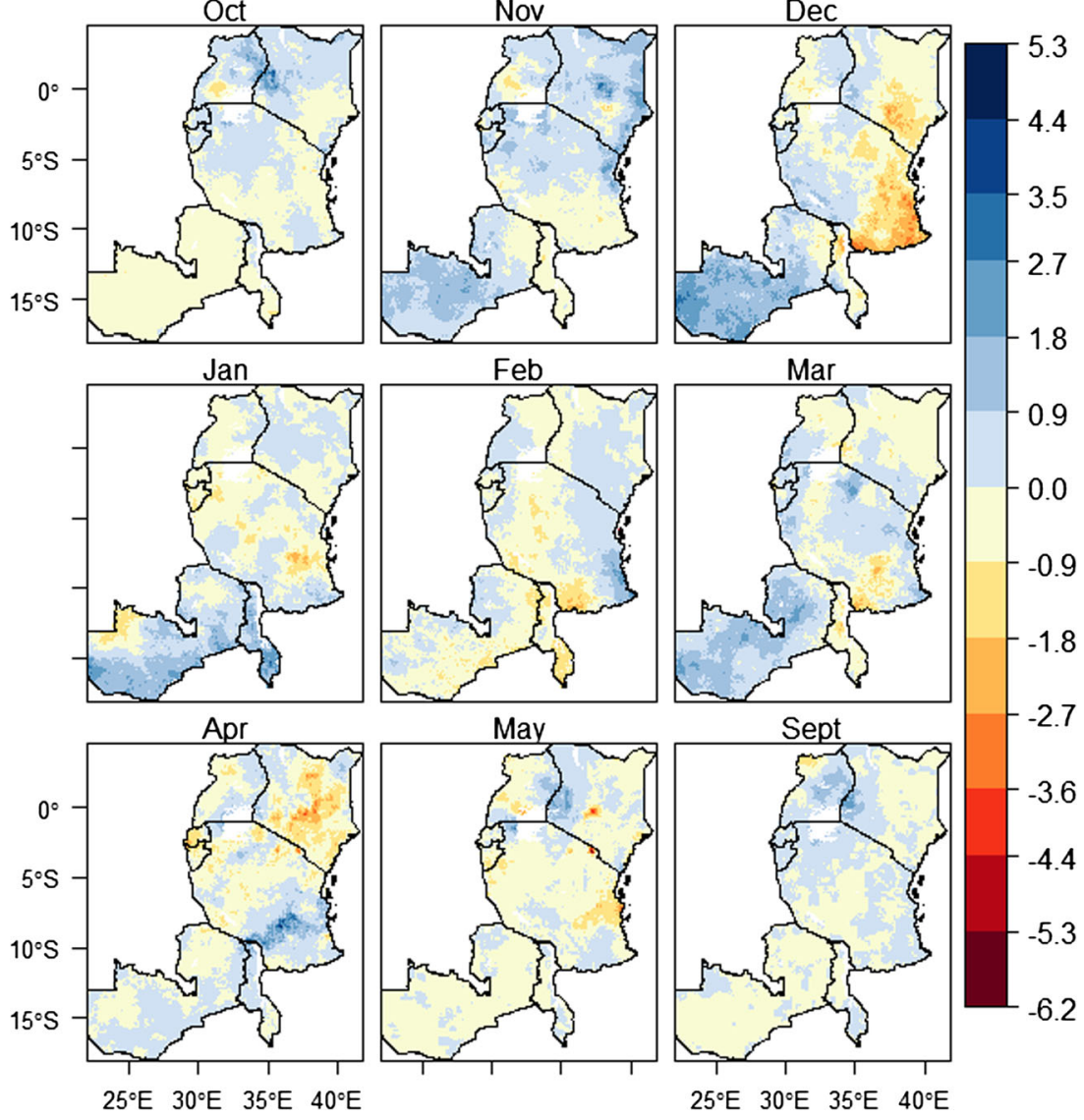

evaluating performance of CHIRPS-v2 over six eastern Africa countries using 1200 independent gauge stations. However, CHIRPS-v2 over-estimate rainfall below $100 \mathrm{~mm}$ and underestimate rainfall above $100 \mathrm{~mm}$, as reported in recent studies (Trejo et al. 2016; Funk et al. 2015; Toté et al. 2015). The validation exercise revealed that CHIRPS-v2 rainfall data estimated gauge observations with high skill. This demonstrates the potential of application of the dataset for spatial-temporal monitoring of rainfall trends and variability in rural Africa to complement existing sparse gauge network. Such applications are expected to improve agro-advisories and spatial targeting of climate smart agricultural (CSA) technologies. Satellite rainfall estimates cannot totally replace but rather complement gauge observations since reliable records of the latter is used to calibrate the former. Therefore establishment of more gauge stations is still needed considering the prevailing low density of gauge network despite complex topographical landscape.

\subsection{Long-term spatial-temporal variability in rainfall}

The highest variability in annual and monthly rainfall was observed in the most arid area in North-eastern Kenya with maximum CV reaching 55\% (Fig. 6) and 180\% (Fig. 7) respectively. The high variability in monthly rainfall compared to annual rainfall implies that in most instances the total annual rainfall remained relatively stable but the intra-year seasonality is highly heterogeneous. The high inter-annual variability signifies increased instances of extreme events such as droughts in the last four decades in the ESA region (Guan et al. 2014). This has serious implications on agricultural production considering that success or failure of crops is more dependent on temporal distribution rather than total amount of rainfall during the growing season (Ngetich et al. 2014).

Annual rainfall anomalies revealed above normal rainfall occurred across the region in 1997 and 2006 that is attributed to El Nino effect (Siderius et al. 2018). Severe droughts were recorded in West Kenya (1984), South East Tanzania (2003 and 2005) and Northern Uganda (2009). The periodic droughts not only increase yield losses (Adhikari et al. 2015) but also hinder adoption of CSA technologies (Niles et al. 2015).

\subsection{Long-term monotonic trends in rainfall}

Two contiguous zones with significant increase in annual rainfall ( 0.1 to $15 \mathrm{~mm}$ year $^{-1}$ ) were identified in Southern Zambia and in the northern part of the Lake Victoria Basin in Western Kenya and Eastern Uganda (Fig. 8b). This is in agreement with Maidment et al. (2015) who observed a similar increasing rainfall trend in Southern Zambia (0.04 $\mathrm{mm} \mathrm{day}^{-1}$ year $^{-1}$ ) 
Fig. 10 Significant $(p<0.1)$ trends for monthly rainfall $\left(\mathrm{mm} \mathrm{year}^{-1}\right)$ for the period between 1981 and 2017 in Eastern and Southern Africa region. Significant slopes were extracted from Fig. 9

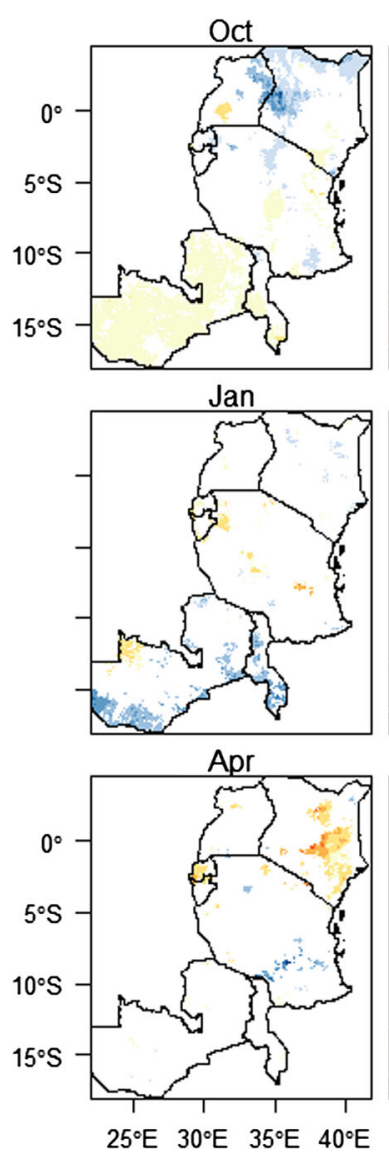

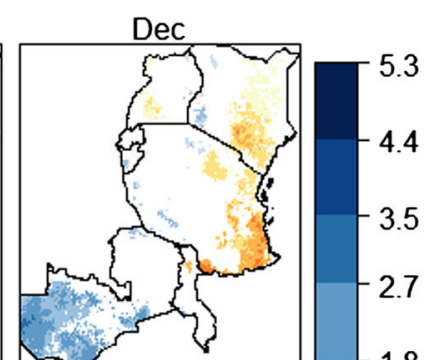

$-1.8$
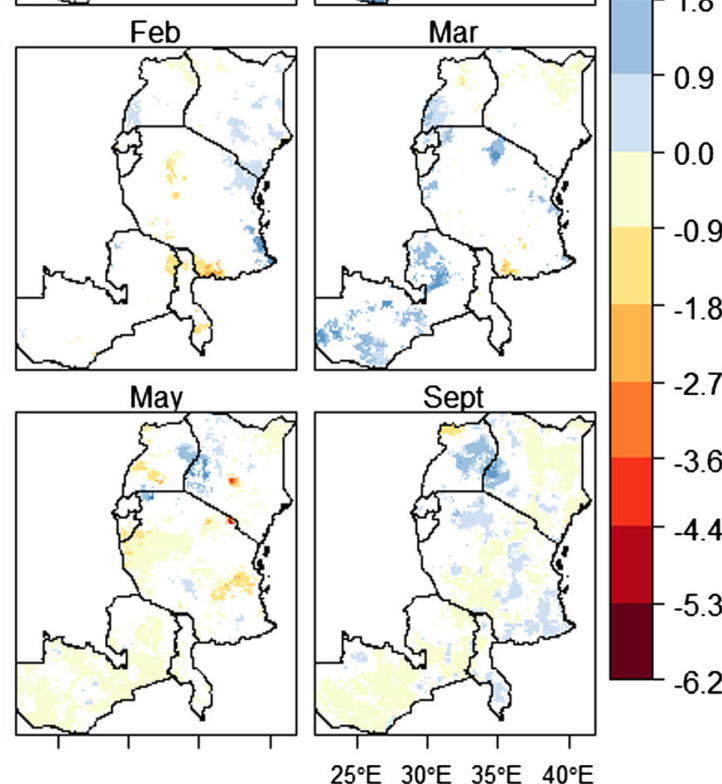

and the Lake Victoria Basin $\left(<0.02 \mathrm{~mm}^{-1 a y}{ }^{-1}\right.$ year $\left.^{-1}\right)$ using CHIRPS-v1 data from 1983 to 2008 that were resampled to much coarser 2.5 degrees grids $(\sim 275 \mathrm{~km}$ at equator). Maidment et al. (2015) further reported that the increasing annual rainfall in Southern Africa was driven mainly by more DJF rains that are attributed to sea surface temperature patterns, particularly the Pacific Walker Circulation. Similarly, our results show that the significant increase in annual rainfall in Southern Zambia is largely driven by more December rains.

Several studies also reported significant increase in rainfall in Lake Victoria Basin across Kenya and Uganda. For example, Kizza et al. (2009) analysed rainfall trends within 20 gauge stations in the Basin and found that positive trends do predominate especially in the Northern part of the Basin. Onyutha (2016a) observed increases of $\sim 0.006 \mathrm{~mm}$ day year ${ }^{-1}$ $\left(\sim 2.19 \mathrm{~mm} \mathrm{year}^{-1}\right)$ in South-east Uganda within Lake Victoria Basin. However, our results show that the significant increases in annual rainfall within Lake Victoria Basin (Fig. 8b) was largely driven by significant increases in the September and October rain (Fig. 10). This concurs with Kizza et al. (2009) that reported significant trends for short rains (OND) compared to long rains (MAM) in the same Basin. The significant decrease in annual and OND rainfall in central West Uganda agrees with a study by Diem et al. (2014) that reported significant decrease in June to December rains in the same region.
They observed that the decline extended further westward towards the Congo Forest and is mainly driven by Atlantic multidecadal oscillation (AMO) during boreal summer and autumn.

The observed highest decline around Mt. Kilimanjaro $\left(20 \mathrm{~mm} \mathrm{year}^{-1}\right)$ is much higher than -1.35 to $7.26 \mathrm{~mm} \mathrm{year}^{-1}$ decline reported for the period 1973 to 2013 in the southern slopes of the mountain (Otte et al. 2017). But that study covered limited altitudinal range (750-1430 $\mathrm{m}$ a.s.l.) and attributed the decline to El Nino Southern Oscillation (ENSO) and Indian Ocean dipole (IOD). Our study observed a large significant decline in April and May rains in Central to South and Northern Kenya which is corroborated by Williams and Funk (2011) who observed similar magnitude of decline in the same area. The authors attributed this drying trend to the westward extension of warm air (Walker Circulation) primarily driven by increased warming of the sea surface temperature over the Indian Ocean. The observed significant decline in long season (MAM) rainfall in Kenya and Uganda contradicts the general projections of increasing rainfall in East Africa (Otte et al. 2017; IPCC 2014).

\subsection{Significance and potential applications of results}

Analysing both inter-annual and intra-annual trends in rainfall offer intuitive information on dynamics of soil moisture in 
rain-fed systems because an area might have the same total annual rainfall but have contrasting spatial-temporal differences in seasonality (Guan et al. 2014). Analysis of multidecadal climatic trends is required for developing robust climate adaptation strategies (Recha et al. 2016). Traditionally, climatic trends are deciphered from stationary gauge stations that have low density and significant data gaps in ESA region. Therefore the per pixel analysis of rainfall trends in this study compliments or compensates for sparse rain gauges to improve agro-advisory services in ESA region. Moreover, the approach undertaken in this paper to analyse rainfall trends and variability in a transboundary ecosystem is expected to promote harmonisation of climate change adaptation and resilience policies across the ESA region.

Information presented in this paper provide spatial evidence to support agronomic and crop breeding programs to setup empirical experiments aimed at developing cultivars and management practices adapted to climatic trends in each pixel. Crop breeders could target zones that exhibit significant increase or decrease in rainfall to set up multi-locational trials for developing cultivars adapted to specific climatic regimes. Similarly, agronomists would be interested in setting up of trials for testing genotype*environment*management outcomes to develop recommendation domains for CSA practices. Maps on spatial-temporal variations and trends of monthly and annual rainfall generated in this study would be key inputs in spatially explicit models (e.g. Muthoni et al. 2017; Rubiano et al. 2016) that generate specific recommendation domains for specific basket of technologies based on crop trials in diverse rainfall regimes.

\subsection{Limitations of the study}

The skill of the satellite rainfall estimates over the study region exhibit high spatial variability due to influence of climate, topography and seasonal rainfall patterns (Dinku et al. 2018; Kimani et al. 2017). Other uncertainties may arise from temporal sampling, error in algorithms and satellite instruments themselves (Ayehu et al. 2017). Similar to other hybrid rainfall products, CHIRPS-v2 has inherent systematic biases emanating partly from low density and decreasing rate of reporting from existing stations over time in Africa that lead to insufficient representation of rainfall variability (Dinku et al. 2018; Kimani et al. 2018). These systematic biases decrease as the time step of rainfall estimates are aggregated from daily to annual timescale (Kimani et al. 2018; Dembélé and Zwart 2016). The accuracy of rainfall estimates is reduced by orographic processes at high elevations and frontal systems along the coastlines and around inland water bodies (Dinku et al. 2018; Kimani et al. 2018). In East Africa, several hybrid satellite rainfall products under-estimate rains at elevation below $2500 \mathrm{~m} \mathrm{(m)} \mathrm{above} \mathrm{sea} \mathrm{level} \mathrm{(a.s.l.)} \mathrm{and} \mathrm{tend} \mathrm{to} \mathrm{over-estimate}$ above that elevation threshold due to orographic processes
(Kimani et al. 2017). CHIRPS-v2 data over-estimate long season rains (MAM) over mountainous regions in East Africa, that is attributed to increased rainfall amounts emanating from deep convective systems (Kimani et al. 2017). Some algorithms for estimating gridded rainfall products uses coarse resolution TIR data, for example, CHIRPS-v2 uses TRMM data with $0.25^{\circ}$ to produce dataset at $0.05^{\circ}$ resolution (Table 1), this can explain its tendency to over-predict lowintensity rainfall since averaging over larger areas increases frequency of rainfall events (Toté et al. 2015). Algorithms based on TIR sensors have poor detections at fine spatial and temporal resolutions although they perform better when aggregated to coarser resolutions.

Different algorithms are designed to monitor certain aspects of rainfall variability, for example TAMSAT algorithms are optimised for drought monitoring and therefore it accurately capture more frequent low rainfall but under-estimate high magnitude and total rainfall (Toté et al. 2015). However recent evaluation studies (Dinku et al. 2018; Ayehu et al. 2017; Kimani et al. 2017; Toté et al. 2015) have demonstrated that CHIRPS-v2 product has higher skills to estimate many aspects of rainfall variability compared to TAMSAT-v2/3 and ARC-v2 that were developed specifically for monitoring rainfall in Africa continent. Moreover, there are recent advances towards developing more robust methods for correcting systematic biases in satellite rainfall estimates such as Bayesian bias correction (Kimani et al. 2018).

\section{Conclusions}

This study analysed the spatial and temporal variability and monotonic trends in rainfall in seven countries in the ESA region. The validation of CHIRPS-v2 satellite rainfall estimates revealed high skill for estimating gauge observations in ESA region $(\mathrm{KGE}=0.68)$. It also showed high temporal agreement $(r=0.72)$ while also preserving total amount $(\beta=0.99)$ and variability $(\gamma=0.8)$ compared to gauge observations. CHIRPS-v2 rainfall estimate provides reliable spatially explicit information on amount and variability of rainfall to complement sparse rain gauge network in ESA region. Both annual and monthly rainfall was highly variable in North-eastern Kenya and most stable in Western Uganda. Annual rainfall anomalies revealed spatial-temporal distributions of droughts and above normal rains that are associated with floods. Two contiguous zones with significant increase in annual were identified in Southwestern Zambia and in the northern part of the Lake Victoria Basin between Western Kenya and Eastern Uganda. Information generated in this paper could be used to inform targeting of appropriate adaptive measures across multiple sectors and ecosystems. 
Acknowledgements The authors thank the two anonymous reviewers for their very constructive comments on earlier draft of the paper.

Funding information This study was funded by USAID through grant numbers: AID-BFS-G-11-00002 and MTO 069018 under the Feed the Future initiative to support Africa RISING program.

Open Access This article is distributed under the terms of the Creative Commons Attribution 4.0 International License (http:// creativecommons.org/licenses/by/4.0/), which permits unrestricted use, distribution, and reproduction in any medium, provided you give appropriate credit to the original author(s) and the source, provide a link to the Creative Commons license, and indicate if changes were made.

Publisher's Note Springer Nature remains neutral with regard to jurisdictional claims in published maps and institutional affiliations.

\section{References}

Adhikari U, Nejadhashemi AP, Woznicki SA (2015) Climate change and eastern Africa: a review of impact on major crops. Food Energy Secur 4:110-132. https://doi.org/10.1002/fes3.61

Arkin PA, Meisner BN (1987) The relationship between large-scale convective rainfall and cold cloud over the western hemisphere during 1982-84. Mon Weather Rev 115:51-74. https://doi.org/10.1175/ 1520-0493(1987)115<0051:TRBLSC >2.0.CO;2

Asadullah A, McIntyre N, Kigobe M (2008) Evaluation of five satellite products for estimation of rainfall over Uganda. Hydrol Sci J 53: 1137-1150. https://doi.org/10.1623/hysj.53.6.1137

Ashouri H, Hsu K-L, Sorooshian S et al. (2014) PERSIANN-CDR: daily precipitation climate data record from multisatellite observations for hydrological and climate studies. Bull Am Meteorol Soc 96:69-83. https://doi.org/10.1175/BAMS-D-13-00068

Ayehu GT, Tadesse T, Gessesse B, Dinku T (2017) Validation of new satellite rainfall products over the Upper Blue Nile Basin, Ethiopia. Atmos Meas Tech Discuss 2017:1-24. https://doi.org/10.5194/amt2017-294

Bartzke GS, Ogutu JO, Mukhopadhyay S, Mtui D, Dublin HT, Piepho HP (2018) Rainfall trends and variation in the Maasai Mara ecosystem and their implications for animal population and biodiversity dynamics. PLoS One 13:e0202814. https://doi.org/10.1371/journal. pone. 0202814

Craparo ACW, Van Asten PJA, Läderach P, Jassogne LTP, Grab SW (2015) Coffea arabica yields decline in Tanzania due to climate change: global implications. Agric For Meteorol 207:1-10. https:// doi.org/10.1016/j.agrformet.2015.03.005

Dembélé M, Zwart SJ (2016) Evaluation and comparison of satellitebased rainfall products in Burkina Faso, West Africa. Int J Remote Sens 37:3995-4014. https://doi.org/10.1080/01431161.2016. 1207258

Diem JE, Ryan SJ, Hartter J, Palace MW (2014) Satellite-based rainfall data reveal a recent drying trend in central equatorial Africa. Clim Chang 126:263-272. https://doi.org/10.1007/s10584-014-1217-x

Dinku T, Ceccato P, Grover-Kopec E, Lemma M, Connor SJ, Ropelewski CF (2007) Validation of satellite rainfall products over East Africa's complex topography. Int J Remote Sens 28:1503-1526. https://doi. org/10.1080/01431160600954688

Dinku T, Funk C, Peterson P, Maidment R, Tadesse T, Gadain H, Ceccato $P$ (2018) Validation of the CHIRPS satellite rainfall estimates over Eastern of Africa. Q J R Meteorol Soc:1-21 https://doi.org/10.1002/ qj. 3244
Funk C, Peterson P, Landsfeld M et al (2015) The climate hazards infrared precipitation with stations - a new environmental record for monitoring extremes. 2:150066. https://doi.org/10.1038/sdata. 2015.66

Goenster S, Wiehle M, Gebauer J, Mohamed Ali A, Stern RD, Buerkert A (2015) Daily rainfall data to identify trends in rainfall amount and rainfall-induced agricultural events in the Nuba Mountains of Sudan. J Arid Environ 122:16-26. https://doi.org/10.1016/j. jaridenv.2015.06.003

Guan K, Good SP, Caylor KK, Sato H, Wood EF, Li H (2014) Continental-scale impacts of intra-seasonal rainfall variability on simulated ecosystem responses in Africa. Biogeosciences 11: 6939-6954. https://doi.org/10.5194/bg-11-6939-2014

Gupta HV, Kling H, Yilmaz KK, Martinez GF (2009) Decomposition of the mean squared error and NSE performance criteria: implications for improving hydrological modelling. J Hydrol 377:80-91. https:// doi.org/10.1016/j.jhydrol.2009.08.003

Hamed KH, Rao AR (1998) A modified Mann-Kendall trend test for autocorrelated data. J Hydrol 204:182-196. https://doi.org/10. 1016/S0022-1694(97)00125-X

Hijmans RJ (2015) Raster: geographic data analysis and modeling. https://CRAN.R-project.org/package=raster. Accessed 10/10 2015

Huffman GJ, Bolvin DT, Nelkin EJ, Wolff DB, Adler RF, Gu G, Hong Y, Bowman KP, Stocker EF (2007) The TRMM multisatellite precipitation analysis (TMPA): quasi-global, multiyear, combined-sensor precipitation estimates at fine scales. J Hydrometeorol 8:38-55. https://doi.org/10.1175/JHM560.1

Hurst HE (1951) Long-term storage capacity of reservoirs. Trans Am Soc Civ Eng 116:770-799

IPCC (2014) Africa. In: Change IPoC (ed) Climate change 2014 -impacts, adaptation and vulnerability: part B: regional aspects: working group II contribution to the IPCC fifth assessment report: volume 2: regional aspects, vol 2. Cambridge University Press, Cambridge, pp 1199-1266. https://doi.org/10.1017/CBO9781107415386.002

Kampata JM, Parida BP, Moalafhi DB (2008) Trend analysis of rainfall in the headstreams of the Zambezi River Basin in Zambia. Phys Chem Earth Parts A/B/C 33:621-625. https://doi.org/10.1016/j.pce.2008. 06.012

Kendall MG (1975) Rank correlation methods, 4th edn. Charles Grifn, London

Kimani M, Hoedjes J, Su Z (2017) An assessment of satellite-derived rainfall products relative to ground observations over East Africa. Remote Sens 9:430. https://oi.org/10.3390/rs9050430

Kimani M, Hoedjes J, Su Z (2018) Bayesian bias correction of satellite rainfall estimates for climate studies. Remote Sens 10. https://doi. org $/ 10.3390 /$ rs 10071074

Kindt R, Coe R (2005) Tree diversity analysis. A manual and software for common statistical methods for ecological and biodiversity studies. vol ISBN 92-9059-179-X. World Agroforestry Centre (ICRAF), Nairobi, Nairobi

Kizza M, Rodhe A, Xu C-Y, Ntale HK, Halldin S (2009) Temporal rainfall variability in the Lake Victoria Basin in East Africa during the twentieth century. Theor Appl Climatol 98:119-135. https://doi. org/10.1007/s00704-008-0093-6

Kling H, Fuchs M, Paulin M (2012) Runoff conditions in the upper Danube basin under an ensemble of climate change scenarios. $\mathrm{J}$ Hydrol 424-425:264-277. https://doi.org/10.1016/j.jhydrol.2012. 01.011

Kumar S, Graham J, West AM, Evangelista PH (2014) Using districtlevel occurrences in MaxEnt for predicting the invasion potential of an exotic insect pest in India. Comput Electron Agric 103:55-62. https://doi.org/10.1016/j.compag.2014.02.007

Kummerow C, Hong Y, Olson WS, Yang S, Adler RF, McCollum J, Ferraro R, Petty G, Shin DB, Wilheit TT (2001) The evolution of the Goddard Profiling Algorithm (GPROF) for rainfall estimation from passive microwave sensors. J Appl Meteorol 40:1801-1820. 
https://doi.org/10.1175/1520-0450(2001)040<1801:TEOTGP >2.0. $\mathrm{CO} ; 2$

Lobell DB, Bänziger M, Magorokosho C, Vivek B (2011) Nonlinear heat effects on African maize as evidenced by historical yield trials. Nat Clim Chang 1:42-45. https://doi.org/10.1038/nclimate1043

Maidment RI, Allan RP, Black E (2015) Recent observed and simulated changes in precipitation over Africa. Geophys Res Lett 42:81558164. https://doi.org/10.1002/2015GL065765

Maidment RI, Grimes D, Black E, Tarnavsky E, Young M, Greatrex H, Allan RP, Stein T, Nkonde E, Senkunda S, Alcántara EMU (2017) A new, long-term daily satellite-based rainfall dataset for operational monitoring in Africa. Scientific Data 4:170063. https://doi.org/10. 1038/sdata.2017.63

Mann HB (1945) Nonparametric tests against trend. Econometrica 13: 245-259. https://doi.org/10.2307/1907187

Menne MJ, Durre I, Vose RS, Gleason BE, Houston TG (2012) An overview of the global historical climatology network-daily database. J Atmos Ocean Technol 29:897-910. https://doi.org/10.1175/ jtech-d-11-00103.1

Muthoni FK, Baijukya F, Bekunda M et al. (2017) Accounting for correlation among environmental covariates improves delineation of extrapolation suitability index for agronomic technology packages. Geocarto Int:1-23. https://doi.org/10.1080/10106049.2017. 1404144

Ngetich KF, Mucheru-Muna M, Mugwe JN, Shisanya CA, Diels J, Mugendi DN (2014) Length of growing season, rainfall temporal distribution, onset and cessation dates in the Kenyan highlands. Agric For Meteorol 188:24-32. https://doi.org/10.1016/j. agrformet.2013.12.011

Nicholson SE (2016) An analysis of recent rainfall conditions in eastern Africa. Int J Climatol 36:526-532. https://doi.org/10.1002/joc.4358

Niles MT, Lubell M, Brown M (2015) How limiting factors drive agricultural adaptation to climate change. Agric Ecosyst Environ 200: 178-185. https://doi.org/10.1016/j.agee.2014.11.010

Novella NS, Thiaw WM (2013) African rainfall climatology version 2 for famine early warning systems. J Appl Meteorol Climatol 52:588606. https://doi.org/10.1175/jamc-d-11-0238.1

Ochieng J, Kirimi L, Mathenge M (2017) Effects of climate variability and change on agricultural production: the case of small scale farmers in Kenya. NJAS - Wageningen J Life Sci 77:71-78. https://doi.org/10.1016/j.njas.2016.03.005

Odongo VO, van der Tol C, van Oel PR, Meins FM, Becht R, Onyando J, $\mathrm{Su} Z$ (2015) Characterisation of hydroclimatological trends and variability in the Lake Naivasha basin, Kenya. Hydrol Process 29: 3276-3293. https://doi.org/10.1002/hyp.10443

Onyutha C (2016a) Geospatial trends and decadal anomalies in extreme rainfall over Uganda, East Africa. Adv Meteorol 2016:15-15. https://doi.org/10.1155/2016/6935912

Onyutha C (2016b) Identification of sub-trends from hydrometeorological series. Stoch Environ Res Risk Assess 30:189205. https://doi.org/10.1007/s00477-015-1070-0

Onyutha C (2016c) Statistical uncertainty in hydrometeorological trend analyses. Adv Meteorol 2016:26-26. https://doi.org/10.1155/2016/ 8701617

Otte I, Detsch F, Mwangomo E, Hemp A, Appelhans T, Nauss T (2017) Multidecadal trends and interannual variability of rainfall as observed from five lowland stations at Mt. Kilimanjaro, Tanzania. J Hydrometeorol 18:349-361. https://doi.org/10.1175/jhm-d-160062.1

Patakamuri SK (2018) modifiedmk: modified Mann Kendall Trend Tests. CRAN. https://CRAN.R-project.org/package=modifiedmk. Accessed 08/08 2018

R Core Team (2018) R: a language and environment for statistical computing. R Foundation for Statistical Computing. https://www.Rproject.org/. Accessed 10/29 2017
Recha JW, Mati BM, Nyasimi M, Kimeli PK, Kinyangi JM, Radeny M (2016) Changing rainfall patterns and farmers' adaptation through soil water management practices in semi-arid eastern Kenya. Arid Land Res Manag 30:229-238. https://doi.org/10.1080/15324982. 2015.1091398

Rubiano MJE, Cook S, Rajasekharan M, Douthwaite B (2016) A Bayesian method to support global out-scaling of water-efficient rice technologies from pilot project areas. Water Int 41:290-307. https:// doi.org/10.1080/02508060.2016.1138215

Sen P (1968) Estimates of the regression coefficient based on Kendall's tau. J Am Stat Assoc 63:1379-1389

Sheffield J, Goteti G, Wood EF (2006) Development of a 50-year highresolution global dataset of meteorological forcings for land surface modeling. J Clim 19:3088-3111. https://doi.org/10.1175/JCLI3790

Siderius C, Gannon KE, Ndiyoi M, Opere A, Batisani N, Olago D, Pardoe J, Conway D (2018) Hydrological response and complex impact pathways of the 2015/2016 El Niño in Eastern and Southern Africa. Earth's Future 6:2-22. https://doi.org/10.1002/ 2017EF000680

Spearman C (1904) The proof and measurement of association between two things. Am J Psychol 15:72-101

Theil H (1950) A rank-invariant method of linear and polynomial regression analysis. Nederlandse Akademie van Wetenschappen Series A: 386-392. https://doi.org/10.1007/978-94-011-2546-8_20

Toté C, Patricio D, Boogaard H, van der Wijngaart R, Tarnavsky E, Funk C (2015) Evaluation of satellite rainfall estimates for drought and flood monitoring in Mozambique. Remote Sens 7:1758-1776. https://doi.org/10.3390/rs70201758

Trejo FJP, Barbosa HA, Peñaloza-Murillo MA, Moreno MA, Farías A (2016) Intercomparison of improved satellite rainfall estimation with CHIRPS gridded product and rain gauge data over Venezuela. Atmósfera 29:323-342. https://doi.org/10.20937/ATM. 2016.29.04.04

Williams AP, Funk C (2011) A westward extension of the warm pool leads to a westward extension of the Walker circulation, drying eastern Africa. Clim Dyn 37:2417-2435. https://doi.org/10.1007/ s00382-010-0984-y

Xie P, Arkin PA (1997) Global precipitation: a 17-year monthly analysis based on gauge observations, satellite estimates, and numerical model outputs. Bull Am Meteorol Soc 78:2539-2558. https://doi. org/10.1175/1520-0477(1997)078<2539:GPAYMA>2.0.CO;2

Yue S, Pilon P, Cavadias G (2002a) Power of the Mann-Kendall and Spearman's rho tests for detecting monotonic trends in hydrological series. J Hydrol 259:254-271. https://doi.org/10.1016/S00221694(01)00594-7

Yue S, Pilon P, Phinney B, Cavadias G (2002b) The influence of autocorrelation on the ability to detect trend in hydrological series. Hydrol Process 16:1807-1829. https://doi.org/10.1002/hyp.1095

Zambrano-Bigiarini M (2018) hydroGOF: goodness-of-fit functions for comparison of simulated and observed hydrological time series. R package version 03-10. https://doi.org/10.5281/zenodo.840087

Zambrano-Bigiarini M, Nauditt A, Birkel C, Verbist K, Ribbe L (2017) Temporal and spatial evaluation of satellite-based rainfall estimates across the complex topographical and climatic gradients of Chile. Hydrol Earth Syst Sci 21:1295-1320. https://doi.org/10.5194/hess21-1295-2017

Zampieri M, Ceglar A, Dentener F, Toreti A (2017) Wheat yield loss attributable to heat waves, drought and water excess at the global, national and subnational scales. Environ Res Lett 12:1-11. https:// doi.org/10.1088/1748-9326/aa723b

Zipper SC, Qiu J, Kucharik CJ (2016) Drought effects on US maize and soybean production: spatiotemporal patterns and historical changes. Environ Res Lett 11:094021 